\title{
Autosomal Recessive Osteopetrosis
}

National Cancer Institute

\section{Source}

National Cancer Institute. Autosomal Recessive Osteopetrosis. NCI Thesaurus. Code C129733.

An autosomal recessive form of osteopetrosis caused by mutation(s) in at least 8 genes related to osteoclast function. This condition is characterized by the failure of osteoclasts to resorb bone, resulting in impaired bone modeling/remodeling, and skeletal frag ility despite increased bone mass; it is also associated with hematopoietic insufficiency, hypocalcemia, disturbed tooth eruption, nerve entrapment syndromes, and growth impairment. Some cases are also associated with progressive neurological deterioration. 